\title{
Analysis of Digital Transformation challenges to overcome by Banks and Financial Institutions in Sri Lanka
}

\author{
A study among the Sri Lankan Fintech \\ J. A. R. C. Jayalath ${ }^{\mathrm{a}}$, S. C. Premaratne ${ }^{\mathrm{b}}$ \\ a vl.ravinduj@icbtcampus.edu.lk, ${ }^{\mathrm{b}}$ samindap@uom.lk \\ ${ }^{a}$ Department of Information Technology, International College of Business \& Technology, Sri Lanka \\ ${ }^{b}$ Department of Information Technology, University of Moratuwa , Sri Lanka
}

\begin{abstract}
The banking and finance sector is one of the highly competitive industries in Sri Lanka and as a result of this it has been evident that the industry is facing challenges to further grow their business also due to most of the leading institutions are capable of providing similar services to the customers due to maintaining of similar scale products and services and similar standards due to strict regulations from Central Bank as well. Therefore, all the established financial institutions are looking at digital transformations as a priority in addition to the other business development strategies to achieve market diversification by developing new business opportunities considering the generation effect with the help of emerging technologies.

The Digital Transformation initiatives taken by most institutions have faced several challenges due to lack of comprehensive digital strategy, non-identification of proper process re-engineering requirements, and non-selection of optimized technology used to deliver the digital business solutions. Factors such as defining a comprehensive digital strategy with strong leadership, transformation of existing processes to compatible with digital products and services, usage of right and the cost-effective technology, customer engagement and customer service are some of the key factors that have a great impact in delivering successful digital business solutions combining with digital technology.
\end{abstract}

Keywords: Digital Transformation, Technology, Digital Strategy, Banking, Finance, Challenges, Process Transformation.

\section{Introduction}

In the year 2021, out of ten most valuable brands in Sri Lanka, six are financial brands according to Brand Finance which indicates the profitability and competitiveness of the industry. As a result of this high competition, almost all the institutions are compelled to maintain similar services; hence it was challenging for them to grow their revenue further due to this high competition. To overcome this situation, financial institutions are actively looking at new business models and a comprehensive corporate strategy to be 
sustainable in this competitive market environment and achieve steady business growth in terms of revenue with increased market share and brand equity. To achieve the above outcomes of the new business model, they are actively looking at the digital transformation to achieve market diversification by introducing new products to new market segments. This has been a reality due to supporting factors such as the digital initiatives by the government agencies, development of supporting infrastructure such as telecommunications, smartphone and internet penetration, digital-based customer identifications and primarily due to higher digital literacy of young generation customers. Financial institutions have the opportunity to convert their traditional businesses models in to digital based solutions and expand their market share with reduced cost and higher customer satisfaction with the help of new digital based products and services while reaching to a new segment of customers which has a direct impact to the brand equity due to the thinking pattern of especially the young generation and due to the needs of millennial consumers which they need to look at remodelling their operational procedures while incorporating with resilient strategies in place adopting with relevant digital transformation supported technologies with Fintech initiatives to overcome the challenges faced in current economic context especially in a situation like present Covid-19 global pandemic.

Definition of a comprehensive strategy is one of the most important criteria in the digital transformation with the re-engineering of the processes to cope up with digital business models. However, the Banking and Financial Institutions are finding many challenges which they need to overcome to full fill a successful digital journey to achieve the specified business outcomes which they need to look at defining the relevant frameworks, including right technological tools combining with right strategy that the organization should incorporate with a proper procedure to define a successful digital business outcome. With the above facts in mind and with the right technologies to support the digital business development model, they need to identify how this digital business development strategy can help them to improve its brand equity, customer satisfaction, increase the market share and increase the revenue by achieving the market diversification.

\section{Definition of digital transformation approach}

Organizations need to define the key factors driving the success of the proposed digital business criteria. One of the key aspects of the digital transformation is defining the digital business development strategy for the organization incorporating with the corporate strategy with a clear leadership with top management commitment. Measurable key performance indicators such as brand equity, revenue growth, market share, and customer satisfaction need to be defined in the strategy to achieve them in certain time periods. The performance has to be measured regularly to track their progress. It necessary to identify the right and affordable technologies that are going to be used in supporting this digital business development model with 
the involvement digital technology teams and experts who are capable of delivering them faster since the delivering of the products at the right time is highly critical for the organization to go ahead with the competition as part of technology strategy and road map. In some contexts, the existing processes defined for the manual business models might not be well optimized for the digital business models hence the expected outcomes of digital such as customer convenience or the time reduction to deliver the end product or service might not be achieved. In some instances, the existing process might not be suitable at all for a digital business model. Hence it is highly required to identify the relevant processes, optimize and re-engineer them, make new processes to comply with digital delivery to achieve successful outcomes of digital. Then it is essential to maintain customer engagement and quantify the customer reach and improve them continuously. No matter how superior the digital product or service has been developed, if the customer awareness or the customer engagement is not there once again, the truly expected outcomes of digital will not be achieved.

\subsection{Digital Transformation Strategic Objectives}

Strategic planning comes as a key business aspect of the organization which defines the success of any proposed business model which would be one of the major aspects for the success of the digital transformation as well which defines the success of the defined outcomes with the correlation of other relevant supporting areas like digital technology, measuring of the key performance indicators expected in the proposed digital business, budget allocation, analysis of possible risks that can be encountered and the relevant remediations to mitigate those risks, marketing strategy with market analysis, financial forecasting etc. On the other hand, aligning the business with corporate objectives to govern with a defined leadership with top management commitment such as through a position like Chief Digital Officer or a Chief Innovation Officer with a clear guidance is a major success criterion to achieve the market performance. Therefore, the financial institutions need to incorporate their digital business proposal as a part of the corporate objectives with the technology innovation as a combination of the coordination, importance, and linking of newly proposed digital business development model in the company. One of the key outcomes of the growth of digital business strategy is technological innovation and bringing the right technology with the right expertise to implement those technologies by identifying the need of the technological innovations and strategy guiding the acquisition and deployment of technological resources for competitive growth.

Technology innovation plays a critical part in providing required IT solutions combining with IT strategy, IT Systems and IT infrastructure to support the digital transformation aspects together with aligning with IT road map for next couple of years to give technological support to align the relevant products and services, processes and structures, supply chain and sales channels to go hand in hand with technology for the business 
development to achieve the benefit of digital transformation with business aspects. It is essential to focus on relevant new technology areas such as Industry 4.0, Robotic Process Automation with the aim of process optimization in relevant areas in order to achieve above to develop a comprehensive digital business strategy while considering the products, services and relevant key business models by aligning technology and commercial strategies together. Above mentioned digital transformation in relevant areas support the firm in formulating a comprehensive digital business strategy with the control of main elements like technological innovations, value added services for customer convenience, structural changes, and required commercial aspects which work in value creation in terms of customer convenience and introducing new product and services. Organization structures need to be re-aligned not only in products, services and processes as specified above but also in the human resource skills in the areas of both technical skills and non-technical skills to full fill the digital business requirements in the organization structure by assigning relevant responsibilities to handle the digital business by improving the expertise of existing employees and recruiting the required experts from the industry to achieve competitive business advantage which highlights the need of transformation, leadership and a comprehensive vision to deliver the results to the target market.

\subsection{Technological Aspects of Digital Transformation}

Innovative technology aligning with corporate strategy plays a major role in developing a digital business strategy by providing correct technology at correct time to enhance the business opportunities and provide customer. In addition to this, it is highly important for the organization to identify the right and affordable technology to minimize the cost and faster delivery. Fintech collaborations can support in great aspects for the established financial institutions to implement the technology effectively by using the expertise of startups contributing with value creation.

Customer relationship management, customer engagement, measuring customer satisfaction, target marketing with social media campaigns, and cross selling with social mining are key aspects defining a successful digital transformation outcome. To achieve these aspects there are various technologies such as AI, RPA, Data Mining \& Big Data Analytics, CRM, Augmented Reality, IoT, Chat Bots, e-KYC, Face Recognition, bio metrics, open APIs, etc. that support in building a comprehensive digital platform by utilizing the benefit of internet penetration and smart phone penetration and their associated developments. Financial institutions can get the benefits by utilizing these right technological innovations by the way people work and share, the way business processes are being carried out, the way customers are served and gathering of customer insights with the support of technology along with information which are connected supporting businesses to evolve beyond the geographical borders while operating from one place with increased efficiency and reduced risk. 
With solid leadership and using the correct affordable technology, the organization can enhance business opportunities with the right business practices, process transformation, and customer experience to get the real outcome of digital business strategy.

\subsection{Process Transformation Aspects of Digital}

Transforming of the business processes to align with company's corporate strategic objectives is highly important to achieve a successful outcome of digital, hence this will be highly important for the digital transformation strategy where the existing manual and lengthy processes need to be transformed to support efficient digital business models aligning with digital business strategy to achieve customer convenience and faster output. It is necessary to go through the existing business processes and identify the required modifications to adjust them and to align them with the digital business strategy and formulate new processes required for successful digital delivery. Organizational centric, customer-centric, sales and financial centric models need to be considered in terms of achieving main aspects such as primary service providers, resource requirements, value creation, customer relationship management, cost structures, customer segmentation and main revenue generation areas since digital transformation highly requires to change business aspects like business processes which will improve the digital transformation businesses outcomes with enhanced business models and features of supportive technologies which encourage organizations to use these models to plan different and react to digital transformations and innovate required new business models.

\subsection{Customer Engagement}

According to above analysis in terms of building strategy, process transformation and implementation of technology to support successful digital outcomes, the primary success factor will be decided based on the reaching of the digital products and services to the end customers and the level of customer satisfaction that they experience via the digital products and services. Customer Relationship Management (CRM) is one of the highly critical factors in digital transformation and implementing in digital business model therefor CRM solutions can be implemented to cater this requirement with the support of technology evolutions to track and maintain this relationship. In addition to this, the digital business models have to be customer-focused, and maintaining continuous customer engagement is crucial. Therefore, identifying and measuring the customers' experience with the products and services offered by the organization is very important. It helps organizations build relevant strategies, policies, and frameworks to enhance and strengthen the digital business approach with a customer centric view point. When designing the digital business model it is necessary to evaluate organization structure, relevant processes, business models in the mind of customer value creation while providing many benefits to companies with value added services for consumers with a higher level of service 
and better customer relationship and fair cost structures for products and services with innovation to gain advantages in the competition, higher revenue with higher customer retention and better customer experience. Areas like data analytics, data science, search engine optimization and social mining can support in identifying the customer insights, customer trends and provide customized solutions based on the demand.

\section{Analysis of the external and internal factors affecting the digital transformation}

When formulating a comprehensive digital transformation strategy as specified above it is highly important to consider the external and internal factors that can affect negatively as well as positively for the successful delivery of digital outcomes and it is required to take remedial actions to overcome the negative factors and strengthen the positive factors with the use of market analysis models such as SWOT, PESTEL, Porters five forces and Porters Diamond model. Contingency plans need to be defined for the situations arise due to external environmental factors such as political instability and adverse economic conditions such as the inflation and currency deprecation. Legal compliance such as GDPR compliance which are mandatory legal compliance requirements for digital financial solutions such privacy of customers need to be discussed to implement and keep provision for further enhancement from the inception. It is important to consider positive factors such as government digital initiatives, increase of digital literacy of customers, development of cutting-edge technologies and development of underline infrastructure required for digital business model which can be effectively used for the benefit of the digital business model. In addition to that, it is beneficial to identify the company's internal environmental factors that can be positively considered for the success of the digital strategy and manage the weakness in existing processes and improve the thinking of the organization's employees for the benefit of the digital business proposal. It is necessary to define the required strategies to manage the competition which are coming from established financial institutions and from the new start-up fintech companies with innovative ideas and effectively managing the suppliers and customers with the consideration of other factors such as knowledge and expertise, cost and funding, technology, managing the demand, partnership with relevant supporting industries while avoiding any business impacts due to monopoly and the contingency planning is required for the disasters such as due to act of god.

\subsection{Market Analysis}

An analysis based quantitative and qualitative aspects on market conditions need to be done which is used to understand the market volume and market size, different customer segments, buying patterns of the customers, competitor analysis, economic conditions, etc. which the financial institutions need to look at market analysis based on demographic and geographic segmentation, target market identification including market size and growth rate, market need identification such as market trends, competitor analysis, barriers to 
enter in to market and the regulatory requirements. Since new proposed products and services require digital literacy it is important to do consider that when doing market segmentation. Some of the important sample data that can be obtained from the Department of Statistics useful for the market analysis, segmentation, position and targeting are given below.

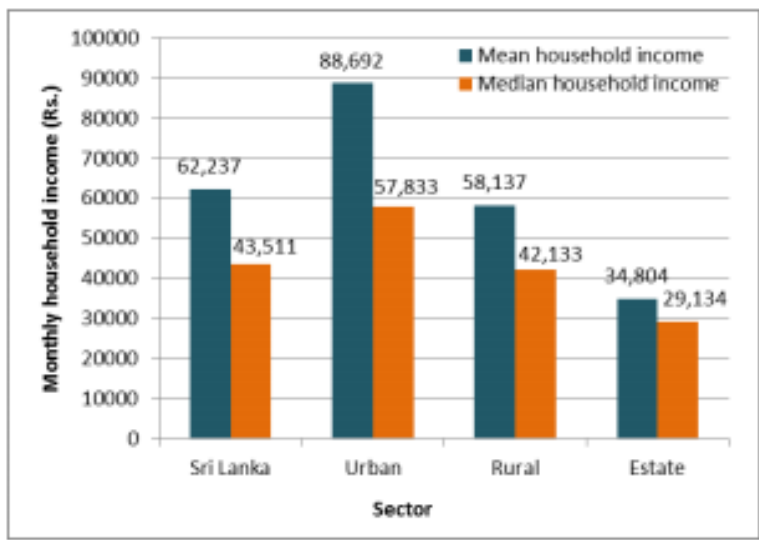

Figure 1: House Hold Income

\begin{tabular}{|c|c|c|c|c|}
\hline Sector/District & $\begin{array}{l}\text { Income } \\
\text { receivers } \\
\text { mean in. } \\
\text { come (Rs.) }\end{array}$ & $\begin{array}{l}\text { Income re- } \\
\text { ceivers me- } \\
\text { dian income } \\
\text { (Rs.) }\end{array}$ & $\begin{array}{l}\text { Household } \\
\text { size }\end{array}$ & $\begin{array}{l}\text { No.of income } \\
\text { receivers in the } \\
\text { household }\end{array}$ \\
\hline Srilanka & 33.894 & 23.260 & 38 & 18 \\
\hline \multicolumn{5}{|l|}{ Sector } \\
\hline Urban & 46,383 & 30,000 & 4.0 & 1.9 \\
\hline Rural & 32,134 & 22,792 & 3.8 & 1.8 \\
\hline Estate & 16,940 & 13,692 & 4.1 & 2.0 \\
\hline \multicolumn{5}{|l|}{ District } \\
\hline Colombo & 51,962 & 33,000 & 40 & 20 \\
\hline Gampaha & 40,174 & 28,386 & 3.8 & 1.8 \\
\hline Kalutara & 35,674 & 24,000 & 3.9 & 1.9 \\
\hline Kandy & 29,714 & 21,600 & 3.8 & 1.9 \\
\hline Matale & 30,660 & 20,814 & 3.7 & 18 \\
\hline Nuwara Eliya & 23,945 & 16,071 & 4.1 & 1.9 \\
\hline Galle & 34,406 & 24,179 & 3.7 & 18 \\
\hline Matara & 28,687 & 21,000 & 3.8 & 1.9 \\
\hline Hambantota & 33,717 & 23,705 & 3.8 & 18 \\
\hline Jaffna & 22,692 & 16,000 & 4.2 & 2.1 \\
\hline Mannar & 25,650 & 21,033 & 4.2 & 1.8 \\
\hline Vavunia & 28,039 & 20,833 & 3.9 & 21 \\
\hline Mullaitivu & 18,461 & 12,864 & 3.8 & 1.7 \\
\hline Kilinochchi & 19,800 & 18,369 & 3.9 & 16 \\
\hline Batticaloa & 25,577 & 19,983 & 3.7 & $1.6 \mathrm{P}>\mathrm{l}$ \\
\hline Ampara & 28,353 & 23.000 & 3.9 & 15 \\
\hline Trincomalee & 28,900 & 22,278 & 3.9 & 1.6 \\
\hline Kurunegala & 32,575 & 21,600 & 3.6 & $1.8 \mathrm{P}-\mathrm{l}$ \\
\hline Puttalam & 34,844 & 23,000 & 3.7 & 18 \\
\hline Anuradhapura & 35,259 & 23,787 & 3.6 & 1.7 \\
\hline Polonnaruwa & 35,044 & 22,000 & 3.7 & 1.8 \\
\hline Badulla & 29.641 & 20,000 & 3.8 & 1.8 \\
\hline Moneragala & 29,590 & 21,423 & 3.7 & 1.6 \\
\hline Ratnapura & 25,366 & 18,200 & 3.7 & 1.9 \\
\hline & & & & \\
\hline
\end{tabular}

Table 1: Top house hold income districts

\begin{tabular}{|l|r|r|r|}
\hline Gender, Age group, & \multicolumn{3}{|c|}{ Computer literacy rate (\%) } \\
\cline { 2 - 4 } Educational attainment and & $\mathbf{2 0 1 8}$ & $\mathbf{2 0 1 9}$ & $\mathbf{2 0 2 0}$ \\
\cline { 2 - 4 } Sri Lanka & $\mathbf{2 7 . 5}$ & $\mathbf{3 0 . 1}$ & $\mathbf{3 2 . 0}$ \\
By Sex & & & \\
Male & 29.7 & 32.1 & 33.9 \\
Female & 25.4 & 28.3 & 30.4 \\
By Age group(years) & & & \\
$5-9$ & 11.2 & 14.3 & 14.0 \\
$10-14$ & 37.4 & 40.4 & 45.0 \\
$15-19$ & 56.6 & 63.8 & 67.6 \\
$20-24$ & 56.2 & 58.0 & 63.6 \\
$25-29$ & 46.9 & 51.5 & 51.0 \\
$30-34$ & 33.9 & 40.0 & 41.7 \\
$35-39$ & 26.5 & 28.9 & 31.1 \\
$40-49$ & 20.1 & 20.9 & 22.0 \\
$50-59$ & 11.3 & 12.1 & 13.5 \\
60-69 & 5.7 & 6.2 & 6.3 \\
By Educational attainment & & & \\
No schooling & 1.2 & 1.1 & 1.3 \\
Below grade 6 & 9.4 & 10.2 & 10.0 \\
Grade 6-10 & 17.8 & 20.3 & 21.7 \\
G.C.E (O/L) & 39.1 & 41.8 & 45.9 \\
G.C.E. (A/L) and above & 70.2 & 71.4 & 74.0 \\
By Language literacy & & & \\
Sinhala & 34.4 & 36.9 & 39.7 \\
Tamil & 28.3 & 31.2 & 32.3 \\
English & 67.6 & 70.7 & 72.7 \\
\hline
\end{tabular}

Table 2: Computer literacy based on age 


\subsection{Risk Assessment}

In addition to these factors, comprehensive risk assessment to identify the risks and define mitigation factors are highly required for the resilience of the digital transformation and the digital business model. Some of the sample risk factors such as loss of business due to unavailability of digital products and services due to IT system failures, supplier delays and inefficiencies, natural disaster, the resignation of key employees, poor customer service, similar or better products and services introduced by the competitors, data breaches as a result of cyber-attacks, etc. need to be considered with the impact and proposed actions to eliminate and mitigate the risks.

\subsection{Other areas to assess}

In addition to above analysis, definition of the key departments in the organization involved in the delivery of the defined digital business model with clear roles and responsibilities, comprehensive financial model such as working capital requirements, cash budgets, budgeted statement of financial position, break even analysis, etc. to quantify the relevant business outcomes are some of the other key aspects to consider in delivering a successful digital outcome and overcome the challenges faced in digital transformation delivery phase.

\section{Conclusion}

It is highly challenging for financial institutions to execute a successful digital transformation journey and achieve successful business outcomes unless they clearly identify the above-mentioned key requirements and the challenges that can occur by not addressing these aspects properly with the key requirements to take remedial actions. Establishment of a proper vision, strategy and leadership considering with cultural, competencies and human resource capabilities and operations, process transformation with technology innovation and partners to implement them, customer engagement and customer relationship management with market analysis including segmentation, positioning and targeting, risk assessment and financial analysis are some of the key aspects to analyse and address to overcome these challenges.

With the fusion of technology and business strategy, digital transformation strategies create the foundation of organization for digital required business models with clear vison establishment for future positioning with foster digital mindset and clear commitment of transformation in the strategy. Financial Institutions need to formulate the strategy with a mind that digital is a value creation which they need to give a clear leadership to the digital business strategy to facilitate faster innovations and prototypes to make the digital strategy a success. In addition to this, adaptive culture with proper capabilities, digital skills, acquire, retain and attract new talents, process re-engineering to comply with digital strategy are highly important. And also 
implementing the right and affordable technology such as data analytics, AI, RPA, with required resources is necessary to facilitate digital transformation and grab the business opportunities with a comprehensive sales and marketing plan for continuous customer engagement.

\section{References}

Anna Omarini. (2017) The Digital Transformation in Banking and The Role of FinTechs in the New Financial Intermediation Scenario. International Journal of Finance, Economics and Trade, Vol 1 No 1. pp. 1-6.

Christian Matt, Alexander Benlian, Thomas Hess and Florian Wiesböck. (2016) Options for Formulating a Digital Transformation Strategy.MIS Quarterly Executive Vol 15 Issue 2. pp.123-139.

Christian Matt, Thomas Hess and Alexander Benlian. (2015) Digital Transformation Strategies. Bus Inf Syst Eng 57(5). pp.339-343.

Daniel Schallmo, Luke Boardman and Christopher A. Williams .(2018) Digital Transformation of Business Models. Digital Transformation Now.pp.9-13.

Department of Statistics. (2016) Household Income and Expenditure Survey.

Department of Statistics. (2020) Computer Literacy Statistics - 2020 First six months.

H Gil-Gomez, V Guerola-Navarro, Raul Oltra-Badenes and Jose Antonio Lozano-Quilis. (2020) Customer relationship management: digital transformation and sustainable business model innovation. Economic Research Volume 33 Issue 1. pp. 2733-2750.

I Siaw and A Yu. (2004) An Analysis of the Impact of the Internet on Competition in the Banking Industry, using Porter's Five Forces Model. International Journal of Management; Poole Vol 21, Issue 4. pp.514-523.

Journal of Promotion Management Volume 25, 2019 - Issue 5.pp. 631-639.

Katarzyna Boratyńska. (2019) Impact of Digital Transformation on Value Creation in Fintech Services: An Innovative Approach.

Matthew R Fairholm. (2009). Leadership and Organizational Strategy. The Innovation Journal: The Public Sector Innovation Journal, Volume 14(1), article 3. pp.1-16.

Meeta Dasgupta, R K Gupta and A Sahay. (2011) Linking Technological Innovation, Technology Strategy and Organizational Factors: A Review. Volume 12 issue 2. pp. 257-277.

S. Mithas and H. C. Lucas. (2010) What is Your Digital Business Strategy. IT Professional, vol 1 no 6.pp. 4-6.

Subhankar Das. (2020) Innovations in Digital Banking Service Brand Equity and Millennial Consumerism. Digital Transformation and Innovative Services for Business and Learning . pp.1-18.

T.von Leipzig, M.Gamp, D.Manz, K.Schöttle, P.Ohlhausen, G.Oosthuizen, D.Palm and K.von Leipzig. (2017) Initializing Customerorientated Digital Transformation in Enterprises. Procedia Manufacturing Volume 8.pp. 517-524. 